\title{
Fear or Humour in anti-smoking campaigns? Impact on perceived effectiveness and support for tobacco control Policies
}

\author{
Medo ou Humor em campanhas antitabágicas? O impacto \\ na perceção de eficácia e apoio a políticas antitabágicas
}

Eduardo Silva Reis (http://orcid.org/0000-0002-5092-7985) ${ }^{1}$

Patrícia Paula Lourenço e Arriaga (http://orcid.org/0000-0001-5766-0489) ${ }^{1}$

Octavian Adrian Postolache (http://orcid.org/0000-0001-5055-6347) ${ }^{2}$

${ }^{1}$ CIS-IUL/ISCTE-Instituto Universitário de Lisboa. Av. Forças Armadas 1649026. Lisboa Portugal. eduardoreis12@gmail.com ${ }^{2}$ Instituto de

Telecomunicações. Lisboa Portugal.

\begin{abstract}
Several anti-smoking campaigns have been used for decades to reduce smoking consumption. However, so far, there is no consensus regarding the effectiveness of inducing distinct emotions in reducing smoke consumption. This study tested the effects of two types of anti-smoking ads, inducing fear or humor, on emotions, perceived effectiveness, support for tobacco control policies, urges to smoke, and susceptibility to smoke. Participants ( $N=108 ; 54$ smokers) of both genders were randomly assigned to one of the two following emotion ads condition: fear $(N$ =52) or humor $(N=56)$. During exposure, the continuous flow of their emotions by self-report and physiologically was collected. Measures of ads impact on emotions, perceived effectiveness, urges and susceptibility to smoking, and support for tobacco policies were applied after exposure. The results have shown that fear ads were perceived as more effective and reduced the urges to smoke in smokers. Non-smokers were more supportive of tobacco control policies. In conclusion, this study showed that fear campaigns can reduce the urge to smoke among smokers and are perceived to be more effective. This perceived effectiveness can be partially explained by feelings of fear, regardless the other emotions it also triggers, and of the smoking status.
\end{abstract}

Key words Fear, Humour, Smoking cessation, Health promotion, Health policy
Resumo Várias campanhas antitabágicas são usadas para reduzir o consumo de tabaco. No entanto, até ao momento não existe um consenso sobre a eficácia da indução de emoções específicas nestas campanhas. Este estudo testou os efeitos de dois tipos de campanhas antitabágicas, induzindo Medo ou Humor, nas emoções, na perceção de eficácia das campanhas, no apoio a políticas antitabágicas, no desejo de fumar, e na suscetibilidade para fumar. Os participantes ( $N=108$; 54 fumadores), de ambos os sexos, foram aleatoriamente distribuídos para uma das seguintes campanhas indutoras de emoções: medo $(N=52)$ ou humor $(N=56)$. Durante a exposição, registou-se o fluxo contínuo das emoções autorreportadas e as respostas fisiológicas. Após a exposição avaliou-se o impacto das campanhas nas emoções, na perceção de eficácia, nas políticas antitabágicas, no desejo e na suscetibilidade para fumar. Os resultados evidenciaram que as campanhas indutoras de medo foram percecionadas como mais eficazes $e$ reduziram o desejo de fumar em fumadores. Politicas antitabágicas foram mais apoiadas por não fumadores. Futuramente deverá considerar-se que induzir diferentes emoções em campanhas antitabágicas pode ter efeitos distintos a nível afetivo $e$ cognitivo, com possivel relevância para a mudança comportamental.

Key words Medo, Humor, Abandono do hábito de fumar, Promoção da saúde, Política de saúde 


\section{Introduction}

Every year, more than 7 million people die directly or indirectly due to tobacco consumption and/ or smoking related diseases ${ }^{1}$. Europe specifically has the highest prevalence of tobacco smoking among adults $(28 \%)^{2}$. To fight this epidemic that significantly hampers society's well-being, tobacco control policies have been implemented in many countries, having generally resulted in noteworthy positive changes for public health. For instance, in Brazil a significant reduction in smoking rates and illegal consumption has been registered after implementation of some of the MPOWER measures developed by the World Health Organisation (WHO) ${ }^{3}$. Portugal has also adhered to this initiative, increasing the prices of cigarette packs, prohibiting tobacco related advertising, and greatly limiting exposure to second-hand smoking by forbidding indoor smoking in most commercial facilities. Even though the decreases are not as significant as those found in Brazil, which has experienced a large decline in smoking prevalence - falling from $34.8 \%$ in 1989 to $14.7 \%$ in $2013^{5}$, these measures have been effective in improving overall public health and raising awareness about protective actions towards smoking ${ }^{4}$. Antismoking campaigns have been developed and implemented in these initiatives and have played a crucial role in informing viewers and contributing to attitude and behaviour change. These campaigns aim to intervene in different steps of the initiation, maintenance and cessation process, and also to prevent smoking initiation. Over the last few decades, antismoking ads were conveyed through different channels, such as radio, television, tobacco package warning messages, and now through the Internet. Regardless the channel, the ads usually feature different types of emotional appeals, such as fear, disgust, or humour, to elicit viewer's emotional responses that potentially will facilitate persuasion. Thus far, research on fear appeals suggests these are more persuasive ${ }^{6}$ and also perceived as more effective ${ }^{7-9}$. Additionally, literature states that the more aversive a fearful ad is, the greater the perceived effectiveness against smoking ${ }^{10}$. Previous studies that examined the effectiveness of cigarette health warning labels ${ }^{11,12}$ also found that these aversive warnings seem to stimulate thoughts about quitting smoking and to promote cessation behavior. Furthermore, a past study ${ }^{13}$ has found that even for smokers with stronger affective state reactance, i.e., "negative affect due to perceived manipulation" in response to these warning, greater subsequent cessation attempts have been observed.

Alternatives to fear appeals include the use of humour, but research is scarce on this topic. Halkjelsvic ${ }^{14}$, for example, investigated the effects of three different appeals (fear, disgust, pleasant) on support for tobacco control policies, finding that negative emotional triggers seem to only affect support for tobacco control policies among non-smokers. Regardless of the target emotion, several emotions might be elicited during a campaign $^{15}$, and messages eliciting more than one emotion tend to be more effective ${ }^{16}$. However, research evaluating the continuous changes of emotions (also named emotional flow) during exposure to a campaign is limited ${ }^{15}$.

Research on the urges and on the susceptibility to smoke is also limited. Susceptible smokers are defined as those who have a lack of a firm commitment to not smoke ${ }^{17}$. Investigating the outcomes of different anti-smoking ads on these outcomes is also important as these individuals have twice the risk of starting to smoke $^{18}$. Studies suggest that urges tend to increase when smokers are exposed to negative emotions ${ }^{19,20}$, while susceptibility to smoke is reduced after exposure to anti-smoking campaigns ${ }^{21-23}$.

Our study also considered several theoretical models to understand the potential effects of these campaigns. The Limited Capacity Model of Motivated Mediated Message Processing (LC4MP) $)^{24}$ proposes that the viewer's cognitive resources are limited and several factors related to the viewer (e.g., preferences, emotional states), the medium (e.g., speed of pacing), and the message (e.g., emotional content, arousal) will affect the processes of encoding, storage, and retrieval of the message. Considering that emotional appeals tend to be processed more fully if arousal levels are adequately triggered in viewers, we used moderately arousing ads of both fear and humour and expected them to induce similar arousal on participants.

Another explanation about how fear affects the viewer was provided by Witte's ${ }^{25}$ Extended Parallel Processing Model (EPPM). According to EPPM, the viewer's reaction to fear stimuli is a result of both the perception of threat and viewer's self-efficacy. For a fear appeal to be properly processed, viewers' self-efficacy should be high to overcome either a low or high threat perception. If threat perception is high and the viewer's self-efficacy is low (in a way that there is no information about a salient behaviour that will reduce their perceived danger susceptibility), then 
viewers might avoid the stimulus, or use other defensive ways to process the message ${ }^{26}$. Thus, we included supplementary information in the ads to reduce the participant's perception of threat and increase self-efficacy.

Also relevant is the Transtheoretical Model (TTM) of behavioural change $e^{27}$, as it highlights the role of motivational stages for behavioural change in smokers. According to TTM, individuals have various degrees of contemplation in behavioural change: Precontemplation, Contemplation, Preparation, Action, and Maintenance. To provide a more precise report of smoker's habits and attitudes that might potentially influence participant's responses we assessed both the stages of contemplation to quit smoking and the degree of addiction in smokers.

Based on the literature, we expected that participants exposed to the fear anti-smoking campaigns would perceive these ads as more effective (H1) and be more supportive of tobacco control policies (H2) than participants exposed to the humour campaigns. Additionally, we expected smokers exposed to fear appeals ads (vs. humour ads) to report less urges to smoke (H3), whereas non-smokers exposed to fear appeals ads (vs. humour ads) would report less susceptibility to smoke in the near future (H4). Finally, we expected fear would mediate the effects of the fear appeals on perceived effectiveness (H5), urges to smoke (H6), support for tobacco control policies (H7) and susceptibility to Smoke (H8). No differences on physiological responses (heart rate, skin conductance levels) between conditions were expected to occur.

\section{Method}

\section{Participants}

The sample consisted of 108 volunteers (58 females), aged between 18-51 years ( $M=21.7, S D$ $=5.1)$, mostly undergraduate students $(76.9 \%)$. Smoking status was assessed using a single item in which participants indicated if they smoked, smoked before but didn't smoke at the time of the study, or never smoked. We considered smokers those that only responded that they smoked at the time of the study. Fifty-four were smokers (30 female) and the other fifty-four (28 females) were non-smokers, $\chi^{2}(2 ; N=108)=0.52$, $p=.77$. Regarding readiness to smoke cessation, $83.5 \%$ of smokers reported being in the stages of precontemplation and contemplation, revealing that the majority were not ready to change their smoking behaviour. Most smokers also reported having low nicotine dependence (88.5\%). Thus, we did not test the moderation of these variables on the effects of the campaigns (Table 1).

\section{Measures and materials}

Advertisements. Six video ads, taken from Halkjelsvik ${ }^{14}$, were used to induce either fear or pleasant emotions (humour). Three videos were used in each condition. In the fear condition, one video portrayed a fictional testimonial of a smoker who had a stroke (The Voice Within, 30s); the second included a real testimonial of a smoker on his death bed (Anthony Hicks, 40s); and the third featured a health professional explaining the health risks of smoking and of developing an emphysema (Emphysema, 60s). In the humour condition, the video ads were also originally used by Halkjelsvik ${ }^{14}$ in the control condition, and satirically feature situations related to tobacco consumption. Specifically, one ad is an advert to a product that is meant to help smokers deal with cravings, by featuring an unrealistic scene of a shark attack while a person is unable to stop thinking about cigarettes (Nicorette Shark, 32s); another video presented a fictitious air freshener that releases the scent and the heavy smoke of tobacco at a party (Nicobreeze, 39s); the third ad exposes the problem of second hand smoke, by confronting the unpleasant smell of cigarettes with the smell of flatulence in a public place (Smoke Flatulence, 42s). Participants were exposed to the three anti-tobacco ads of each condition (fear or humour) in a randomized order. Based on the EPPM ${ }^{25}$, the ads ended with specific information about Portuguese treatment centres for smoking cessation. These messages have been added to the original ads.

Emotions. To capture the emotional flow during exposure to the ads, we developed Flowsense, a software that allowed participants to report the type of emotion (joy, sad, fear, disgust, surprise, anger, boredom, and neutral) and their intensity (ranging from 0-10) in real time. Simultaneously, the Levels of Heart Rate (HRLs) and of Skin Conductance (SCLs) were recorded as indexes of arousal. Because of equipment failure, some participants were excluded from the analysis of Flowsense, resulting in a final sample of 61 participants for SCL, and 91 for both HR and continuous report of emotions. Immediately after exposure, participants were asked again to evaluate the emotions they felt by responding to 15 
Table 1. Sociodemographic Characteristics as a Function of Ads Condition.

\begin{tabular}{|c|c|c|c|c|c|c|c|}
\hline & \multicolumn{2}{|c|}{$\begin{array}{c}\text { All sample } \\
(\mathrm{n}=108)\end{array}$} & \multicolumn{2}{|c|}{$\begin{array}{c}\text { Fear Ads } \\
(\mathrm{n}=52)\end{array}$} & \multicolumn{2}{|c|}{$\begin{array}{l}\text { Humor Ads } \\
\quad(n=56)\end{array}$} & \multirow[t]{2}{*}{$\chi^{2}$} \\
\hline & $\mathbf{n}$ & $\%$ & $\mathbf{n}$ & $\%$ & $\mathbf{n}$ & $\%$ & \\
\hline Gender & & & & & & & 0.001 \\
\hline Male & 50 & 46.3 & 24 & 46.2 & 26 & 46.4 & \\
\hline Female & 58 & 53.7 & 28 & 53.8 & 30 & 53.6 & \\
\hline Education & & & & & & & 1.92 \\
\hline High School & 83 & 76.9 & 39 & 75 & 44 & 78.6 & \\
\hline Bachelor & 21 & 19.4 & 12 & 23.1 & 9 & 16.0 & \\
\hline Masters & 3 & 2.8 & 1 & 1.9 & 2 & 3.6 & \\
\hline Other & 1 & 0.9 & - & - & 1 & 1.8 & \\
\hline Occupational Status & & & & & & & 1.44 \\
\hline Worker & 3 & 2.8 & 2 & 3.9 & 1 & 1.8 & \\
\hline Student & 88 & 81.5 & 40 & 76.9 & 48 & 85.7 & \\
\hline Worker-Student & 17 & 15.7 & 10 & 19.2 & 7 & 12.5 & \\
\hline Smoking Status & & & & & & & 0.15 \\
\hline Non-Smokers & 54 & 50 & 27 & 52 & 27 & 48.2 & \\
\hline Smokers & 54 & 50 & 25 & 48 & 29 & 51.8 & \\
\hline Stage of Readiness & 54 & 100 & 25 & 46.3 & 29 & 53.7 & 12.9 \\
\hline Precontemplation & 7 & 13 & 3 & 12 & 4 & 13.7 & \\
\hline Contemplation & 38 & 70.3 & 16 & 64 & 22 & 76 & \\
\hline Preparation & 7 & 13 & 4 & 16 & 3 & 13.3 & \\
\hline Maintenance & 2 & 3.7 & 2 & 8 & - & - & \\
\hline Nicotine Dependence & 52 & 100 & 24 & 46.15 & 28 & 53.85 & 2.17 \\
\hline Low & 46 & 88.5 & 23 & 95.8 & 23 & 82.1 & \\
\hline Moderate & 2 & 3.8 & - & - & 2 & 7.2 & \\
\hline \multirow[t]{2}{*}{ High } & 4 & 7.7 & 1 & 4.2 & 3 & 10.2 & \\
\hline & $\mathbf{M}$ & DP & $\mathbf{M}$ & DP & $\mathbf{M}$ & DP & $\mathbf{F}$ \\
\hline Age & 21.7 & 5.1 & 21.6 & 4.3 & 21.7 & 5.79 & 0.001 \\
\hline
\end{tabular}

items taken from Arriaga and Almeida ${ }^{28}$. Three items were used for each of the following emotions: joy $(\alpha=.96)$, sadness $(\alpha=.91)$, anger $(\alpha=$ $.95)$, fear $(\alpha=.95)$, and disgust $(\alpha=.95)$, through a 7-point Likert scale, ranging from 1 ("I haven't felt the emotion") and 7 ("I felt the emotion very strongly").

Perceived ads effectiveness. A total of 8 items adapted from Kees et al. ${ }^{29}$ were used to measure perceived effectiveness of campaigns to encourage smokers to quit and discourage smoking initiation, with four of these items corresponding to ads effectiveness targeting adolescents or young adults between $18-25$ years $(\mathrm{a}=.89)$, and the remaining four items targeting adults between 2650 years old $(\mathrm{a}=.89)$. An example of an item is "I think the advertisements would encourage adolescents/young adults between 18-25 years who currently smoke to quit". The level of agreement with all eight statements was made through a 5 -point scale, ranging from 1 ("totally disagree") to 5 ("totally agree").

Support for tobacco control policies. The six items present in Halkjelsvic ${ }^{14}$ were used, which were partly based on the Smoking Policy Inventory $^{30}$ to measure attitudes and opinions about tobacco control and smoking policies (e.g., "Smoking should be forbidden in all restaurants and coffee shops"). Participants rated their answers on a 7-point scale ranging from 1 ("Strongly disagree") to 7 ("Strongly agree"). The mean values were computed with higher scores indicating greater support $(\mathrm{a}=.69)$.

Smoking urges. We used the Questionnaire of Smoking Urges - Brief ${ }^{31}$, which is composed by 10 statements about intentions and desires to smoke. Participants were asked to indicate their level of agreement over a 5-point scale ranging 
from 1 ("Strongly disagree") and 5 ("Strongly agree"). The mean values were computed with higher scores indicating greater smoking urges $(\mathrm{a}=.91)$.

Susceptibility to smoking. The Susceptibility to Smoking questionnaire ${ }^{32}$ was used. It is composed by three questions related to the possibility of tobacco consumption in a near future. To be considered "not susceptible to smoking", the participant had to answer "no" and "definitely not" to all questions.

Readiness to smoking cessation. We used an adapted version of the Contemplation Ladder $^{33}$ which follows the $\mathrm{TTM}^{27}$ to identify, in smokers, the motivational stages for the cessation of consumption. This scale is composed of 11 statements (e.g. "I rarely think about changing my smoking behaviours, and I have no plans to change"), numbered from 0 to 10 , and the participant chooses just one statement that best reflects his/hers situation. The corresponding motivational stage is extrapolated according to: precontemplation, from statement 0 to 3 ; contemplation, from 4 to 6 ; preparation, statements 7 and 8; action, statement 9; and maintenance, statement 10 .

Nicotine dependence. The Fagerström Test for Nicotine Dependence ${ }^{34,35}$ was used to measure the degree of urgency to initiate and maintain nicotine consumption according to the smoker's nicotine threshold. This test consists of six questions (e.g. "How soon after you wake up do you smoke your first cigarette?"). Each question has several response options, and each response option is listed with a score that ranges from 0 to 3 . The evaluation is made by the sum of all selected options. The level of nicotine dependence is considered low if the values range from 1-4, moderate if equal to 5 , and high above 5 .

\section{Procedure}

This project was accepted by the Institutional Review Board in which the study took place. Figure 1 provides the flow diagram of participants through the stages of the experiment. All data was collected in a laboratory room with controlled temperature and ambient noise. After signing an informed consent, participants completed the first part of the questionnaires which included sociodemographic data, the Contemplation Ladder scale and the Fagerström Test. To measure physiological responses, electrodes were placed in the non-dominant hand of participants. For SCLs, two disposable Ag-AgCl electrodes with isotonic gel were placed at the medial phalanges of the index and middle finger. For HRLs, three ECG sensors were used: one was placed on the pulse and the other two were placed on the participant's ankles. Conductive "NuPrep" solution was applied to ensure a better recording. Participants were then exposed to a video sequence on a computer screen, composed of three moments: (1) introduction to Flowsense; (2) baseline measure; (3) randomly assignment to one of the two anti-smoking advertisements: fear or humour, in which three ads were presented. The order of the three videos was also randomized. Physiological responses and self-reported emotions were recorded continuously. After exposure we collected data again on self-reported specific emotions, followed by smoking urges (for smokers), susceptibility to smoke (for non-smokers), campaign's perceived effectiveness, and anti-smoking policies. Each session lasted between 30 to 40 minutes. At the end, participants were debriefed, course credits or a small retribution ( $€ 5$ voucher) were given as compensation.

\section{Results}

\section{Manipulation check}

To check whether the manipulation of inducing fear and humour in the anti-smoking ads worked in our sample of participants, we conducted several Student's t-tests, or Welch's $t$-tests instead when the variances across groups were not equal, on participant's self-report of experienced emotions (during and after exposure) and physiological responses (SCL and HR). Detailed statistical results for self-reported measures on emotions are presented in Table 2. Regarding the continuous flow of subjective emotions, participants reported one to six emotions while viewing each video, and a maximum of 16 emotions in each condition $(M=8.19)$. Compared to the humour condition, in the fear condition participants selected significantly more often fear, Welch's $t(55.49)=4.30, p<.001$, and sadness, Welch's $t(51.78)=11.01, p<.001$, felt more intensively fear, Welch's $t(76.30)=3.93, p<.001$, and sadness, Welch's $t(76.78)=10.24, p<.001$, and also reported these two emotions for longer periods of time, Welch's $t(65.25)=3.54, p=.001$ for fear, and Welch's $t(48.28)=9.74, p<.001$, for sadness. In contrast, participants in the humour condition reported significantly more often joy, Welch's $t(70.68)=6.80, p<.001$, disgust, Welch's 


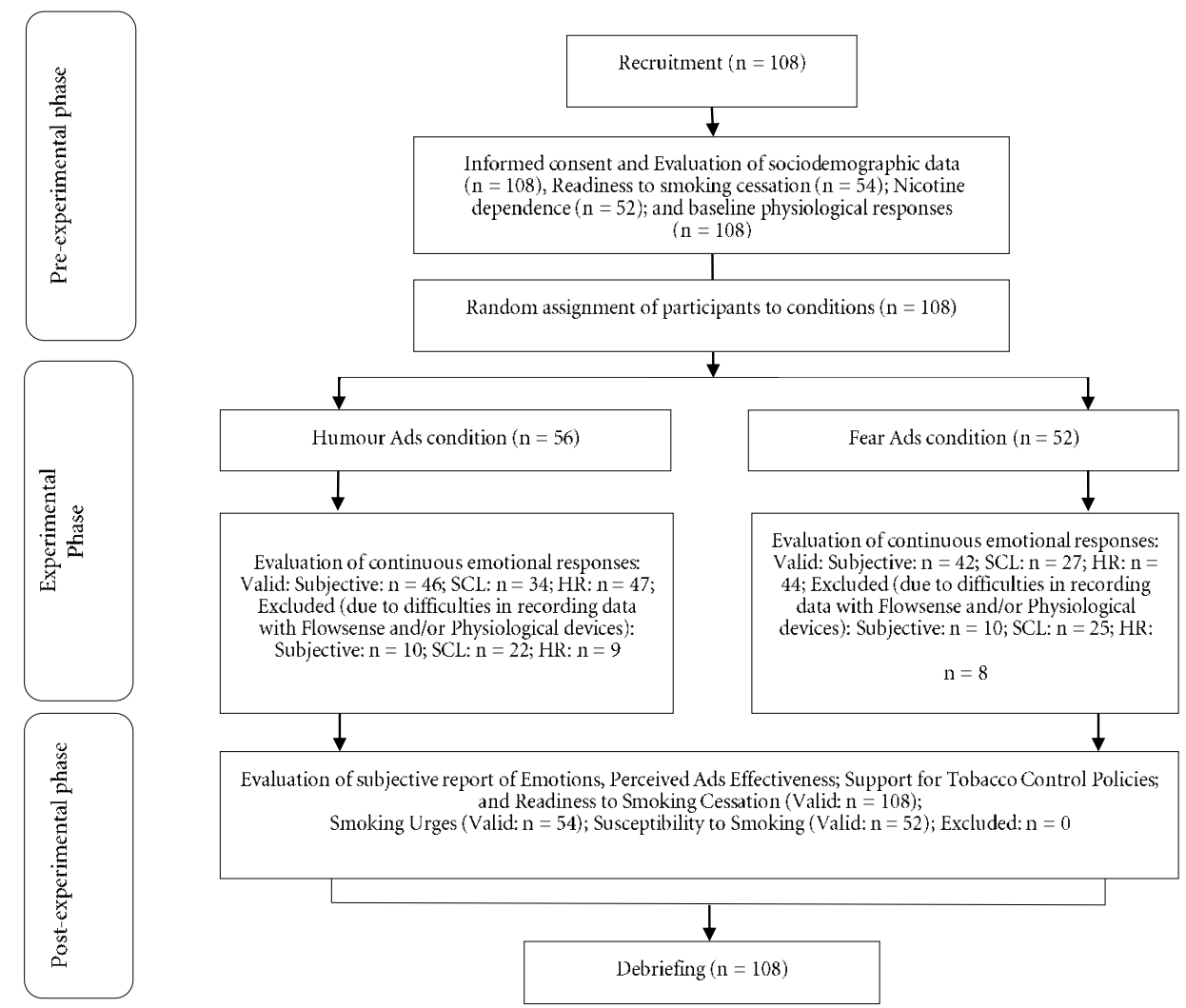

Figure 1. Flow diagram of the randomized allocation of participants to groups based on the Consort 2010 Group.

$t(79.74)=5.13, p<.001$, and neutral states, Welch's $t(85.94)=3.18, p=.002$, than those in the fear condition. Also, in the humour condition (vs. fear condition), the intensity of joy, Welch's $t(84.73)=7.49, p<.001$, and of disgust, were significantly higher, $t(90)=3.67, p<.001$. No statistical differences between ads conditions were found on the number, duration and intensity of anger, boredom, and surprise, $p s>.05$. The results for the emotions reported after exposure are also in line with the continuous measurement, revealing that the fear ads in comparison to the humour ads induced more fear, Welch's $t(85.61)$ $=8.93, p<.001$, but also higher sadness, Welch's $t(92.83)=11.06, p<.001$, and lower feelings of joy, Welch's $t(66.81)=11.23, p<.001$. No dif- ferences were found for disgust and anger, $p s>$ .10. These results showed that our manipulation of fear and humour were as intended, although in the fear condition, sadness was also dominant.

Regarding physiological data, SCLs ranged from $1.19 \mathrm{mS}$ to $9.53 \mathrm{mS}(M=3.55, S D=1.65)$ and HRL range from 54 to $109 \mathrm{bpm}(M=83.47)$. The analyses were then computed by subtracting the participant's baseline levels from the mean levels recorded during ads exposure. Results showed that the mean differences in both SCL, $t(59)=.97, p=.335\left(M_{\text {Fear }}=.93 ; S D_{\text {Humor }}=.54\right.$; $\left.M_{\text {Humor }}=.78 ; S D_{\text {Humor }}=.65\right)$ and HRL, $t(89)=.57$, $p=.569\left(M_{\text {Fear }}=1.43 ; S D_{\text {Humor }}=3.24 ; M_{\text {Humor }}=\right.$ 1.78; $S D_{\text {Humor }}=2.73$ ), were not statistically significant, which indicates that participants expe- 


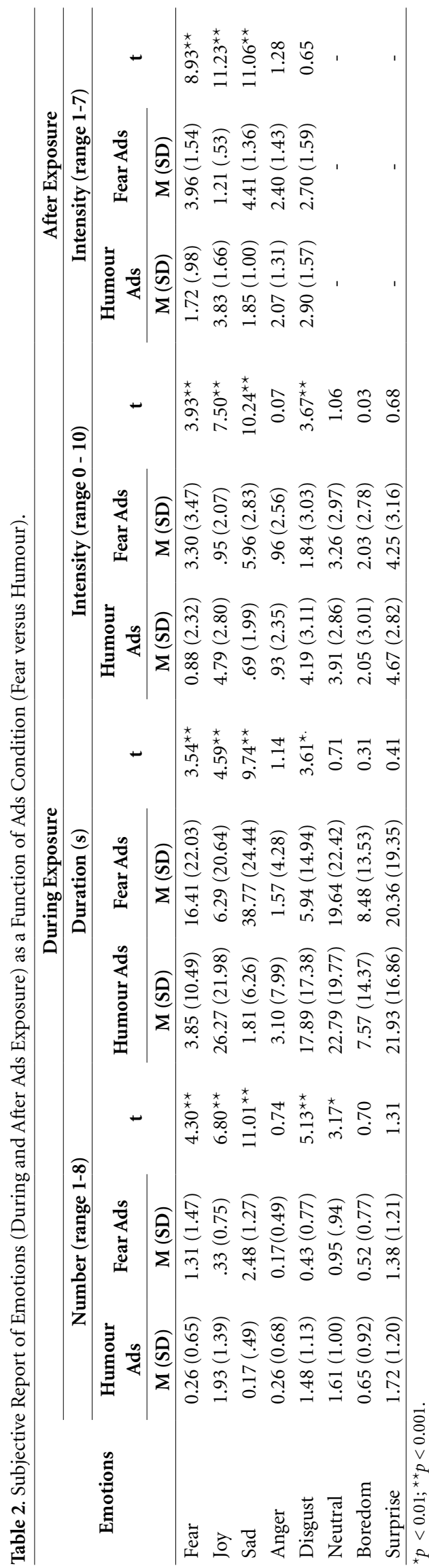

rienced similar levels of physiological arousal in both conditions.

\section{Hypothesis testing}

The results for our main dependent variables as a function of ads conditions are presented in Table 3. For perceived ads effectiveness we conducted a Multivariate Analysis of Variance (MANOVA) 2 (Condition) x 2 (Smoking status) on the two dimensions of perceived effectiveness of the ads as a function of the age target (18-25 and 25-50 years of age). Results showed a significant main effect of ads condition, $F(2,103)=$ $13.74, p<.001, \eta^{2}=.21$. As predicted $(\mathrm{H} 1)$, participants exposed to the fear condition considered the ads more effective in encouraging people to quit smoking and discourage smoking initiation, than those in the Humour condition for both age targets. Results of smoking status and of the interaction between condition X smoking status were both nonsignificant, $p s>.05$.

As in Halkjelsvik's study ${ }^{14}$, the ANOVA 2 (Condition) $\times 2$ (Smoking status) on the tobacco control policies showed only a significant main effect of smoking status, $F(1,104)=17.71, p<$ $.001, \eta_{\mathrm{p}}^{2}=.15$, with non-smokers expressing higher level of agreement with anti-smoking policies $(M=5.25, S D=1.03)$ than smokers $(M=$ $4.33, S D=1.20$ ). No effect of condition, nor a statistically significant interaction were found. Thus, $\mathrm{H} 2$ was not supported.

The results on smoking urges showed significant differences between conditions, $t(52)=2.04$, $p=.047$ : as predicted (H3), smokers in the fear condition reported less urge to smoke $(M=1.74$, $S D=.59)$ than those in the humour condition $(M=2.16, S D=.88)$.

For non-smokers, the distribution of participants reporting susceptibility to smoke in the near future was similar for both conditions, ${ }^{2}(1$, $N=52)=.70, p=.402$, not supporting H4. Overall, $55.8 \%$ participants did not consider themselves to be susceptible to smoke in the near future, with similar percentages in both conditions (25\% in humour; $30.8 \%$ in fear).

Finally, mediational analyses were conducted to test our predictions for the two dependent variables in which we found differences between conditions (i.e., perceived effectiveness and smoking urges). As mediators we included the emotions that showed significant differences between conditions and were correlated with the dependent variables (fear, sadness, joy). As presented in Table 4 , perceived effectiveness was significantly 
Table 3. Perceived Effectiveness, Support for Tobacco Control Policies, Smoking Urges and Susceptibility to Smoke as a Function of Ads Condition (Fear versus Humour).

\begin{tabular}{lccc}
\hline & Humour Ads & Fear Ads & F \\
\cline { 2 - 3 } & M (SD) & M (SD) & (Condition) \\
\hline Perceived Effectiveness of the Ads & & & $13.74^{* *}$ \\
for targets 18-25 years old & $2.38(1.00)$ & $3.26(.99)$ & $20.55^{\star *}$ \\
for targets 26-50 years old & $2.54(1.23)$ & $3.50(1.01)$ & $21.98^{\star *}$ \\
Support for Tobacco Control Policies & $4.33(1.20)$ & $5.25(1.03)$ & .20 \\
Smoking Urges (Smokers) & $M(S D)$ & $M(S D)$ & $t$ \\
& $2.16(.88)$ & $1.74(.59)$ & $2.04^{\star}$ \\
Susceptibility to Smoke (Non-Smokers) & $N(\%)$ & $N(\%)$ & $\chi^{2}$ \\
With Susceptibility & $13(25)$ & $10(19.2)$ & .70 \\
Without Susceptibility & $13(25)$ & $16(30.8)$ & \\
\hline
\end{tabular}

${ }^{*} p<0.05 ;{ }^{* *} p<0.001$.

Table 4. Pearson Correlations Between Postexperimental Report on Emotions, Perceived Ads Effectiveness, and Smoking Urges.

\begin{tabular}{|c|c|c|c|c|}
\hline & \multicolumn{2}{|c|}{$\begin{array}{c}\text { Perceived Effectiveness } \\
\text { of the Ads }\end{array}$} & \multirow[b]{2}{*}{ Total } & \multirow[b]{2}{*}{$\begin{array}{c}\text { Smoking } \\
\text { Urges }\end{array}$} \\
\hline & $\begin{array}{c}\text { for targets } \\
18-25 \\
\text { years old }\end{array}$ & $\begin{array}{c}\text { for targets } \\
26-50 \\
\text { years old }\end{array}$ & & \\
\hline Joy & $-.27^{\star}$ & $-.22^{\star}$ & $-.27^{\star}$ & $.32^{\star}$ \\
\hline Sad & $.43^{* *}$ & $.38^{\star *}$ & $.43^{* *}$ & .06 \\
\hline Fear & $.56^{\star *}$ & $.50^{\star *}$ & $.59^{\star *}$ & -.17 \\
\hline Disgust & .14 & .03 & .09 & -.10 \\
\hline
\end{tabular}

${ }^{*} p<.05 ;{ }^{* *} p<.001$.

correlated with joy $(r=-.27)$, sadness $(r=.50)$ and fear $(r=.59), p s<.05$. Additionally, urges to smoke was positively correlated with joy $(r=.32$, $p<.05)$.

For perceived effectiveness, a multiple mediational analysis was conducted using the macro Process for SPSS ${ }^{36}$. There was a total effect of the fear condition on perceived effectiveness $(B=$ $.88, S E=.19, t=4.59, p<.001, \mathrm{CI}: 0.57,1,26)$, and on feelings of fear $(B=2.23, S E=.25, t=$ $9.07, p<.001 \mathrm{CI}: 1.74,2.72)$, of sadness $(B=2.56$, $S E=.23, t=11.19, p<.001 \mathrm{CI}: 2.19,3.02)$, and of joy $(B=-2.63, S E=.24, t=-19.90, p<.001$ CI:-3.10, -2.15). However, a 95\% bias-corrected bootstrap CI, based on 1,000 bootstrap samples, showed that only fear had a positive effect, which was statistically different from zero on perceived effectiveness $(B=2.23, S E=.24$; point estimate $=$ .73 , Boot CI:.42, 1.08), rather than joy (Boot CI:$.79, .006)$, or sadness (Boot CI:-.32, .40). In addi- tion, there was no evidence that the direct effect of the ads on perceived effectiveness remained significant $(B=.52, S E=.27, p=.054 \mathrm{CI}:-.01$, 1.05). Thus, the effects of the manipulation on perceived effectiveness are dependent only on the feelings of fear the ads evoked. The overall model accounted for $38 \%$ of the variance in perceived effectiveness, $F(4,103)=29.97, p<.001$. The results from the simple mediation revealed that joy has not contributed to explain the effect of exposure to the campaigns on the urge to smoke $(B$ $=.11, S E=.08$; point estimate $=-.30$, with Boot CI:-.84, .24).

\section{Discussion}

This study examined the effect of anti-smoking campaigns inducing humour and fear on the support for tobacco control policies, perceived campaign's effectiveness to reduce or stop smoking behaviours, urges to smoke in smokers, and susceptibility to smoke in non-smokers. Based on the role of emotional flow during exposure to campaigns ${ }^{15,37}$, emotions felt during exposure and physiological responses were recorded continuously through the Flowsense software. In addition, felt emotions were collected after exposure to understand their role in explaining their potential mediator effects on the dependent variables. The ads were successful in manipulating the intended emotions. Moreover, fear ads also evoked higher sadness, probably related to the inclusion of narratives focusing on enduring suffering and losses. The ads were also similar in terms of the physiological arousal they triggered as measured by heart rate and skin conductance. 
Results confirmed the hypothesis predicting that fear-inducing campaigns would be perceived as more effective than humour ads (H1), indicating that fear appeals lead viewers to perceive higher effectiveness of anti-smoking campaigns, a result in line with prior studies ${ }^{7-9}$. Fear was also the only emotion studied explaining this effect (H5), revealing its dominant effect over the emotions that were also triggered by the fear ads, especially sadness. Thus, moderate arousal levels of fear, as indicated by the reduced levels of increased physiological arousal (SCL and HR) and by the subjective report of the intensity of this emotion after exposure $(M=3.96$ on a scale ranging from 1 - barely feel the emotion, to 7 feel the emotion very intensively), seemed to allow participants to process the message's content adequately.

Fear appeals in antismoking campaigns have been investigated over appeals based on positive emotions such as the use of humour or irony in their message. Fear effectiveness has been well documented in past literature and in our findings, but the importance of establishing a comparison between these two emotionally valenced appeals must be highlighted, given the important role that positive emotions also seem to have in attitudinal change and in reaching out different populations ${ }^{38}$. However, this comparison has rarely been done previously in this field, and to the best of our knowledge, no other study compared the perceived effectiveness of these two appeals. Nevertheless, the role of humour versus fear in antismoking campaigns on other outcomes has been investigated, such as the study conducted by Lee and Fergunson ${ }^{39}$ that assessed college students-levels of interest in these two different valenced ads, taking into account their sensation seeking needs. Results indicated that rebellious participants rated the fearful ads as more interesting than the humour inducing ones, something that is consistent with the view that fearful ads may lead to higher recall rates after exposure. However, the authors also indicate that humour appeals can be persuasive agents given that these tend to not elicit defensive mechanisms in the viewers. Thus, the role of humour in antismoking campaigns should not be neglected. Mukherjee and Dubé ${ }^{40}$, for example, showed that when an element of humour is present in a threatening campaign, persuasion is increased compared to having no humorous element. Therefore, while our work follows a trend in investigating how fear can be a persuasive agent in health campaigns, it also provides new insights about the scarcely in- vestigated component of humour in these campaigns. Nevertheless, more research is needed to understand how these ads can be better used to be equally or more effective, considering different targets of the population. Additionally, other types of positive appeals should be considered and evaluated, such as those invoking hope in viewers, attempting to persuade the viewer without priming reactance or defensive responses that may be elicited by the fear appeals. Future studies should consider a profound analysis of how positive appeals influence smoking related outcomes, given that they could be a valuable resource in the on-going worldwide and nationwide efforts to extinguish tobacco use.

In addition, the hypothesis predicting that fear campaigns would produce a higher support for tobacco control policies (H2) was not confirmed. Therefore, the mediational hypothesis (H7) was not tested. We found, however, that non-smokers expressed higher agreement with anti-smoking control policies than smokers, and generally that the vast majority of participants exposed to both campaigns reported high support for tobacco control policies. These results are in line with Halkjelsvic's work ${ }^{14}$, and are very important since they suggest that the on-going efforts made by several country initiatives to overcome this health problem have reinforced anti-tobacco attitudes both in non-smokers and smokers alike. Repeated exposure to antismoking campaigns and significantly increasing the barriers to smoking seem to lead to lifestyle changes in several countries, which culminated in improvements in public health. Yet, our results indicate that specific efforts should be directed at increasing support for tobacco control policies in smokers, while simultaneously maintaining non-smokers' support and avoiding smoking initiation. This is in line with a previous study conducted by Alday et al. ${ }^{41}$ that suggested strong attitudes in favour of antismoking laws by non-smokers after exposure to graphic antismoking ads, and a significant increase in the same attitudes in smokers. Future research should investigate if targeting smokers with more positive appeals, including for example, well-known role models to persuade the viewer with adequate behaviours leads to further increases in the support for tobacco control policies, given that past studies indicate that smoking behaviour is one of the main predictors of opposition to tobacco control policies ${ }^{42,43}$. The lack of support towards these policies may reflect the smoker's concerns with the consequences that such policies can have to themselves, but positive 
appeals could highlight the positive consequences of these policies, possibly generating an empathic response towards a role-model's preferences or an idealized version of the future.

The hypothesis that fear ads would reduce the urge to smoke in smokers, compared to humour ads (H3), was also supported. To our knowledge no previous study has tested the influence of fear-inducing compared to the use of humour in anti-smoking campaigns in the urge to smoke. Previous studies suggested that negative (vs. positive) emotional states are predictors of higher levels of urge to smoke in former smokers, which is in line with our results ${ }^{20,21}$. However, neither fear nor happiness were mediators of the effects of the ads on the urge to smoke (H6). Thus, these results highlight the importance of using fear (and sadness) inducing campaigns, at least for a temporary reduction of the urge to smoke in smokers, and the need for further research on this topic.

The results on susceptibility to smoke amongst non-smokers were similar in both ads conditions, thus not supporting $\mathrm{H} 4$ and $\mathrm{H} 8$. The literature suggests that exposure to anti-smoking media can lower viewers' susceptibility ${ }^{21-23}$, but other characteristics of the campaigns, including the way it is displayed (via text, audio, or audio-visual format) may play an important role and should be investigated.

We should also consider some limitations of our study, such as the use of a sample of convenience, consisting mainly of young participants. Future studies should use different populations. Also, smokers in our sample reported low levels of nicotine dependence and reported not being ready to quit smoking. Thus, the results only apply to participants with these characteristics.

Nevertheless, the methodology and findings from the present study significantly contribute to the on-going discussion about how to properly design and implement health communication campaigns. As part of our procedure, we edited all the antismoking ads to feature self-efficacy increasing messages at the end, something derived from previous knowledge on effective fear appeals, namely the Extended Parallel Processing Model $^{25}$. The inclusion of these characteristics in anti-smoking ads are important, because when the emotional threat is perceived as very high, smokers tend to avoid them, and may even lead to an inadvertent negative reinforcement of the undesired behaviour, as suggested by Witte ${ }^{25}$. Besides the self-efficacy messages, the ads in our study were also designed to trigger moderate levels of arousal on viewers, and consequently our findings suggest a temporary reduction in the urge to smoke in smokers after exposure to the fear appeals. Future studies should take this into consideration as the literature on health communication design and implementation suggests that health campaigns should be developed taking into account the findings from studies that tested theories such as the Elaboration Likelihood Model and the Extended Parallel Processing Model ${ }^{44}$.

Our study also provided a new methodological approach, by assessing both subjective and objective data continuously on the viewer's responses to multimedia antismoking campaigns. Flowsense allowed for a more comprehensive and complete analysis of the emotional responses to the anti-smoking ads by capturing several parameters of participant's emotional flow, such as their frequency, duration, intensity, combined with physiological data. The recording and analyses of the emotional flow are in line with literature recommendations ${ }^{26}$, and can be an important step to provide relevant information related to health communication design.

Finally, the outcomes under investigation in our work are important and novel contributions to the topic of antismoking campaigns. A clear indication of this is the fact that to the best of our knowledge very few or actually no other studies assessed the impact of different antismoking campaigns on the support for tobacco control policies, urges to smoke in smokers and susceptibility to smoke in non-smokers. Future studies should investigate the impact of different types of appeals on these outcomes in different populations.

In conclusion, this study showed that fear campaigns can reduce the urge to smoke among smokers and are perceived to be more effective. This perceived effectiveness can be partially explained by feelings of fear, regardless the other emotions it also triggers, and of the smoking status. 


\section{Collaborations}

The theoretical introduction was written mainly by ES Reis, while the contributions to the methodology were made similarly by the three authors. Flowsense software development was handled by OA Postolache. The reporting of results was mainly done by PPL Arriaga, and the discussion was achieved jointly between the three authors.

\section{References}

1. World Health Organization (WHO). Tobacco. Geneva: WHO; 2018. [cited 2018 Jan 7]. Available from: http://www.who.int/mediacentre/factsheets/fs339/en/

2. World Health Organization (WHO). Data and statistics. Geneva: WHO; 2018. [cited 2018 Jan 7]. Available from: http://www.euro.who.int/en/health-topics/disease-prevention/tobacco/data-and-statistics

3. World Health Organization (WHO). Tobacco control in Brazil. Geneva: WHO; 2015. [cited 2018 Jan 7]. Available from: http://www.who.int/tobacco/about/ partners/bloomberg/bra/en/

4. Nunes E. Programa Nacional para a Prevenção e Controlo do Tabagismo. Lisboa: Direção Geral de Saúde; 2013.

5. Szklo A, Souza MC, Szklo M, Almeida LM. Smokers in Brazil: who are they? Tob Control 2015; 25(5):564-570

6. Manyiwa S, Brennan R. Fear appeals in anti-smoking advertising: How important is self-efficacy? J Mark Manage 2012; 28(11-12):1419-1437.

7. Durkin SJ, Wakefield MA, Spittal MJ. Which types of televised anti-tobacco campaigns prompt more quitline calls from disadvantaged groups? Health Educ Res 2011; 26(6):998-1009.

8. Jónsdóttir HL, Holm JE, Poltavski D, Vogeltanz-Holm $\mathrm{N}$. The role of fear and disgust in predicting the effectiveness of television advertisements that graphically depict the health harms of smoking. Prev Chronic Dis 2014; 11:E218.

9. Vogeltanz-Holm N, Holm JE, Plume JW, Poltavski D. Confirmed recall and perceived effectiveness of tobacco countermarketing media in rural youth. Prev Sci 2009; 10(4):325-334.

10. Volchan E, David IA, Tavares G, Nascimento BM, Oliveira JM, Gleiser S, Szklo A, Perez C, Cavalcante T, Pereira MG, Oliveira L. Implicit motivational impact of pictorial health warning on cigarette packs. PLoS One 2013; 8(8):e72117.

11. Szklo AS, Volchan E, Thrasher JF, Perez C, Szklo M, Almeida LM. Do more graphic and aversive cigarette health warning labels affect Brazilian smokers' likelihood of quitting? Addict Behav 2016; 60:209-212.

12. Thrasher JF, Swayampakala K, Borland R, Nagelhout G, Yong HH, Hammond D, Bansal-Travers M, Thompson M, Hardin J. Influences of self-efficacy, response efficacy and reactance on responses to cigarette health warnings: A longitudinal study of adult smokers in Australia and Canada. Health Commun 2016; 31(12):1517-1526

13. Cho YJ, Thrasher JF, Swayampakala K, Yong HH, McKeever R, Hammond D, Anshari D, Cummings KM, Borland R. Does Reactance against Cigarette Warning Labels Matter? Warning Label Responses and Downstream Smoking Cessation amongst Adult Smokers in Australia, Canada, Mexico and the United States. PLoS One 2016; 11(7):e0159245.

14. Halkjelsvik T. Do disgusting and fearful anti-smoking advertisements increase or decrease support for tobacco control policies? Int J Drug Policy 2014; 25(4):744-747.

15. Nabi RL. Emotional flow in persuasive health messages. J Health Commun 2015 1; 30(2):114-124. 
16. Carrera P, Caballero A, Muñoz D. Comparing the effects of negative and mixed emotional messages on predicted occasional excessive drinking. Subst Abuse 2008; 1:1-7.

17. Polanska K, Wojtysiak P, Bak-Romaniszyn L, Kaleta D. Susceptibility to cigarette smoking among secondary and high school students from a socially disadvantaged rural area in Poland. Tob Induc Dis 2016; 14:28.

18. Pierce JP, Choi WS, Gilpin EA, Farkas AJ, Merritt RK. Validation of susceptibility as a predictor of which adolescents take up smoking in the United States. Health Psychol 1996; 15(5):355-361.

19. Doherty K, Kinnunen T, Militello FS, Garvey AJ. Urges to smoke during the first month of abstinence: relationship to relapse and predictors. Psychopharmacology 1995; 119(2):171-178.

20. Tiffany ST, Drobes DJ. Imagery and smoking urges: the manipulation of affective content. Addict Behav 1990; 15(6):531-539.

21. Aslam SK, Zaheer S, Rao S, Shafique K. Prevalence and determinants of susceptibility to cigarette smoking among school students in Pakistan: secondary analysis of Global Youth Tobacco Survey. Subst Abuse Treat $\operatorname{Pr} 2014$; 9:10.

22. Guindon GE, Georgiades K, Boyle MH. Susceptibility to smoking among South East Asian youth: a multilevel analysis. Tob Control 2008; 17(3):190-197.

23. Veeranki SP, Mamudu HM, Anderson JL, Zheng SM. Worldwide never-smoking youth susceptibility to smoking. J Adolescent Health 2014; 54(2):144-150.

24. Lang A. Motivated cognition (LC4MP): The influence of appetitive and aversive activation on the processing of video games. In: Messarsis P, Humphries L, editors. Digital media: Transformation in human communication. New York: Peter Lang Publishing; 2006. p. 237254.

25. Witte K. Putting the fear back into fear appeals: The extended parallel process model. Commun Monogr 1992; 59(4):329-349.

26. Maloney EK, Lapinski MK, Witte K. Fear appeals and persuasion: A review and update of the Extended Parallel Process Model. Soc Personal Psychol Compass 2011; 5:206-19.

27. Prochaska JO, Diclemente CC. Stages and processes of self-change of smoking: Toward an integrative model of change. J Consult Clin Psych 1983; 51(3):390-395.

28. Arriaga P, Almeida G. [Emotion Factory: The use of film excerpts to induce emotions] Laboratório de Psicologia 2010; 8(1):63-80.

29. Kees J, Burton S, Andrews JC, Kozup J. Tests of graphic visuals and cigarette package warning combinations: Implications for the framework convention on tobacco control. J Public Policy Mark 2006; 25(2):212-223.

30. Velicer WF, Laforge RG, Levesque DA, Fava JL. The development and initial validation of the smoking policy inventory. Tob Control 1994; 3(4):347-355.

31. Cox LS, Tiffany ST, Christen AG. Evaluation of the brief questionnaire of smoking urges (QSU-brief) in laboratory and clinical settings. Nicotine Tob Res 2001; 3(1):7-16.
32. Pierce J, Choi W, Gilpin E, Farkas, A, Merritt, R. Validation of susceptibility as a predictor of which adolescents take up smoking in the United States. Health Psychol 1996; 15(5):355-361.

33. Biener L, Abrams DB. The Contemplation Ladder: Validation of a measure of readiness to consider smoking cessation. Health Psychol 1991; 10(5):360365.

34. Heatherton TF, Kozlowski LT, Frecker RC, Fagerström KO. The Fagerström test for nicotine dependence: A revision of the Fagerström tolerance questionnaire. Brit J Addict 1991; 86(9):1119-1127.

35. Ferreira PL, Quintal C, Lopes I, Taveira N. [Nicotine dependence test: linguistic and psychometric validation of the Fagerström test]. Rev Port Saúde Publica 2009; 27(2):37-56.

36. Hayes AF. An introduction to mediation, moderation, and conditional process analysis: A regression-based approach. New York: Guilford Press; 2013.

37. Nabi RL, Green MC. The role of a narrative's emotional flow in promoting persuasive outcomes. Media Psychol 2015; 18(2):137-62.

38. Hastings G, Stead M, Webb J. Fear appeals in social marketing: Strategic and ethical resons for concern. Psychol Mark 2004; 21(11):961-986.

39. Lee MJ, Ferguson MA. Effects of Anti-Tobacco Advertisements Based on Risk Taking Tendencies: Realistic Fear vs. Vulgar Humor. Journal Mass Commun Q 2002; 79(4):945-963.

40. Mukherjee A, Dubé L. Mixing emotions: The use of humor in fear advertising. J Consum Behav 2012; (11):253-266.

41. Alday J, Murukutla N, Cedillo C, Johns P, Monteiro A, Wakefield M. Smoke-free Sao Paulo: a campaign evaluation and the case for sustained mass media investment. Salud Publica Mex 2010; 52(2):216-225.

42. Hamilton WL, Biener L, Rodger CN. Who supports tobacco excise taxes? Factors associated with towns' and individuals' support in Massachusetts. J Public Health Man 2005; 11(4):333-340.

43. Poland BD, Cohen JE, Ashley MJ, Adlaf E, Ferrence R, Pederson LL, Bull SB, Raphael D. Heterogenity among smokers and non-smokers in attitudes and behavior regarding smoking and smoking restrictions. Tob Control 2000; 9(4):364-371.

44. Noar SM. A 10-year retrospective of research in health mass media campaigns: where do we go from here? $J$ Health Commun 2006; 11(1):21-42.

Artigo apresentado em 18/06/2017

Aprovado em 21/05/2018

Versão final apresentada em 23/05/2018 